\title{
Frying stability of virgin and refined sesame oils as compared to refined olive oil
}

\author{
Reza Farhoosh ${ }^{1}$ and Hasan Salehi ${ }^{1}$ \\ ${ }^{1}$ Ferdowsi University of Mashhad
}

March 14, 2021

\begin{abstract}
Frying stability of two virgin (VSO) and refined (RSO) sesame oils was compared with that of a refined olive oil (ROO). The oils were used to fry potato stripes at $180{ }^{\circ} \mathrm{C}$ and conjugated dienes (CDV), total carbonyls (CV), and thermo-oxidative and hydrolytic polar components were monitored over time. The rate of change in CDV (mmol l-1 h-1) was significantly lower for ROO (0.72) than for VSO (1.00) and RSO (1.84). The change in CV for ROO (2.31 $\mu \mathrm{mol} \mathrm{g}-1 \mathrm{~h}-1)$ was significantly much faster than those for RSO (1.89) and VSO (1.17). Based on the thermo-oxidative polar components, the calculated frying times for VSO, RSO, and ROO were on the order of 32.1, 13.9, and $15.4 \mathrm{~h}$. However, VSO contained significantly the highest contents of hydrolytic polar components over time and RSO exhibited more resistance than ROO on this basis.
\end{abstract}

\section{Introduction}

Frying is one of the most conventional methods of food preparation with annual commercial values of over billions of dollar in the world. During the process, frying oil is exposed to elevated temperatures, atmospheric oxygen, and the moisture released from the food which is being fried. Such a condition results in several deteriorative chemical reactions, including oxidation in the presence of oxygen, hydrolytic alterations due to food moisture, and thermal polymerization at high temperatures (Dobarganes et al., 1988). These could lead to the formation of a wide range of undesirable compounds influencing the sensory properties, toxicity, and nutritional quality of fried foods.

Initial quality and chemical composition of frying oils remarkably affect the reactions occurring during oil deterioration (Farhoosh and Pazhouhanmehr, 2009). High-quality frying oils have been reported to initially have free fatty acids less than $0.1 \%$ (or an acid value, $\mathrm{AV}$, of $\sim 0.2 \mathrm{mg} \mathrm{g}^{-1}$ ), peroxide values (PV) ranging from 0.5 to $1.0 \mathrm{meq} \mathrm{kg}{ }^{-1}$, and smoke points above $200{ }^{\circ} \mathrm{C}$ (Stevenson et al., 1984). Fatty acids as the major components of frying media should be on a specified composition. Polyunsaturated fatty acids (PUFA) are rapidly peroxidized and largely lower the shelf life of fried products. To avoid polymerization, several countries have set limits as low as $2 \%$ for linolenic acid. Monounsaturated fatty acids (MUFA, primarily oleic acid), which are considered to be beneficial from a health standpoint, show high oxidative stability and provide a light taste. Saturated fatty acids (SFA, mainly palmitic and stearic) are stable towards peroxidation and polymerization. However, high SFA levels should be avoided because they adversely affect the sensory attributes (e.g., waxy mouth-feel and dry surface) of fried foods (Boskou, 2003). Apart from the fatty acid composition, tocopherols and phenolic compounds, which are indigenous minor components found extensively in vegetable oils, have been shown to exert an important contribution to the protection of frying oils against thermo-oxidative degradations (Boskou, 2003).

Olive oil is considered to be one of the best candidates for frying purposes (Molina-Garcia et al., 2017). This is due to possessing a prominent and well-balanced chemical composition, being associated with its fatty acid composition constituted primarily of oleic acid $(55-83 \%)$ as well as significant amounts of some tocopherols 
and phenolic compounds with powerful antioxidant activity and health-promoting effects (Bendini et al., 2007). From a commercial point of view, olive oils are categorized as extra virgin, virgin, refined, and just olive oil (Firestone, 2005). Extra virgin and virgin olive oils are made directly from olive fruits with no chemical treatments. Those virgins with high levels of lipid hydroperoxides, acidity, and off-flavors, which are called as lampante, are needed to be refined. Refined olive oils, which are relatively less expensive but lack of any flavor, could be flavored by adding certain quantity of the virgins, being commercially categorized as olive oil. Literature review shows a limited number of comparative studies on the thermo-oxidative stability of different commercial categories of olive oil. Considering the amount of polymeric triglycerides generated over heating of a number of virgin and refined vegetable oils at $170{ }^{\circ} \mathrm{C}$, virgin oils were shown to be of better oxidative stability than the corresponding refined oils (Gertz et al., 2000). In a study on the emission of low molecular weight aldehydes from the oils heated at $180{ }^{\circ} \mathrm{C}$ and $240{ }^{\circ} \mathrm{C}$, there was found very similar results for the extra virgin and refined olive oils (Fullana et al., 2004). There was observed no significant difference between the different commercial categories of olive oil fried at $170{ }^{\circ} \mathrm{C}$ by monitoring a range of oxidation products (Casal et al., 2010).

Sesame oil is another super stable oil which is highly resistant to peroxidation despite its relatively high unsaturation degree. The exceptional stability of sesame oils has been attributed to the presence of sesame seed lignans (e.g., sesamin, sesamolin, and sesamol), tocopherols, and some Millard reaction products (AbouGharbia et al., 2000; Lee et al., 2007; Shahidi and Naczk, 2004). Sesame oil can be produced from unroasted or roasted sesame seeds, which the latter have been reported to contain higher contents of sesamol. In fact, sesamol is formed by thermal hydrolysis of sesamolin, and the rate of this conversion increases at elevated temperatures and longer durations of roasting process (Lee et al., 2010). Cold-pressed or virgin and refined sesame oils are two common commercial types of sesame oil, which both are consumed as salad dressing due to their high degree of unsaturation (Wan et al., 2015). Regardless of some reports dealing with sesame oils blended with other oil sources in order to improve thermo-oxidative and/or frying stability of the final product, literature review shows no individual study on the frying stability of virgin or refined sesame oils. Hence, the aim of this study was to evaluate the frying stability of virgin and refined sesame oils as compared to a commercial refined olive oil.

\section{Materials and methods}

\section{Materials}

Virgin (VSO) and refined (RSO) sesame oils from unroasted sesame seeds with no added antioxidants were supplied by Datis (Yazd, Iran) and were kept at $-18{ }^{\circ} \mathrm{C}$ until analysis. Refined olive oil (ROO) was purchased from a local shop. The standards of fatty acid methyl esters (FAME) and all chemicals and solvents used in experiments were of analytical reagent grade and purchased from Merck (Darmstadt, Germany) and Sigma-Aldrich (St. Louis, MO).

\section{Fatty acid composition}

To prepare FAME, $0.3 \mathrm{~g}$ of the oil samples was dissolved in $7 \mathrm{ml}$ of hexane, followed by vigorous shacking of the solution with $2 \mathrm{ml}$ of $7 \mathrm{~N}$ methanolic potassium hydroxide $(\mathrm{KOH})$ at $50{ }^{\circ} \mathrm{C}$ for $10 \mathrm{~min}$. FAME were identified using an HP-5890 gas chromatograph (Hewlett-Packard, CA, USA) equipped with a CP-FIL 88 (Supelco, Inc., Bellefonte, PA) capillary column of fused silica $(60 \mathrm{~m} \times 0.22 \mathrm{~mm}$ I.D., $0.2 \mu \mathrm{m}$ film) and a flame ionization detector (FID). Nitrogen was used as carrier gas with a flow rate of $0.75 \mathrm{ml} \mathrm{min}^{-1}$. The oven temperature was maintained at $198{ }^{\circ} \mathrm{C}$, and those of injector and detector at $250{ }^{\circ} \mathrm{C}$.

\section{Peroxide value (PV)}

Depending on the extent of peroxidation, $0.01-0.30 \mathrm{~g}$ of the oils were mixed in a disposable glass tube with $9.8 \mathrm{ml}$ of chloroform-methanol $(7: 3 \mathrm{v} / \mathrm{v})$ and vortexed for $2-4 \mathrm{~s}$. Ammonium thiocyanate solution $(50 \mathrm{ml}$, $30 \% \mathrm{w} / \mathrm{v}$ ) was added and the sample was vortexed for $2-4 \mathrm{~s}$. Fifty $\mathrm{ml}$ of iron(II) chloride solution ([0.4-g barium chloride dihydrate dissolved in 50-ml $\left.\mathrm{H}_{2} \mathrm{O}\right]+\left[0.5-\mathrm{g} \mathrm{FeSO}_{4} \cdot 7 \mathrm{H}_{2} \mathrm{O}\right.$ dissolved in 50-ml $\left.\mathrm{H}_{2} \mathrm{O}\right]+[2-\mathrm{ml}$ $10 \mathrm{M} \mathrm{HCl}$, with the precipitate, barium sulfate, filtered off to produce a clear solution]) were added, and the 
sample was vortexed for $2-4 \mathrm{~s}$. After a 5-min incubation at room temperature, the absorbance was read at $500 \mathrm{~nm}$ against a blank containing all the reagents except the sample. Results were expressed in meq of oxygen per kg of oil (Shantha and Decker, 1994).

\section{Acid value (AV)}

The oil samples $(10 \mathrm{~g})$ dissolved in $50 \mathrm{ml}$ of previously neutralized chloroform-ethanol $(50: 50 \mathrm{v} / \mathrm{v})$ were titrated with a solution of $0.1 \mathrm{~N} \mathrm{KOH}$ in ethanol as the standard reagent to a phenolphthalein endpoint. AV was the mg of $\mathrm{KOH}$ consumed to neutralize the free fatty acids present in $1 \mathrm{~g}$ of oil (AOCS Official Method Cd 3d-63, 1993).

\section{Total tocopherols (TT) content}

A calibration curve of $\alpha$-tocopherol in toluene $(0-240 \mu \mathrm{g} / \mathrm{ml})$ was prepared. Five $\mathrm{ml}$ of toluene were added to $100 \pm 10 \mathrm{mg}$ of the oil sample in a 10 - $\mathrm{ml}$ volumetric flask. Three and one-half $\mathrm{ml}$ of 2,2'-bipyridine $(0.07 \% \mathrm{w} / \mathrm{v}$ in $95 \%$ aqueous ethanol $)$ and $0.5 \mathrm{ml}$ of $\mathrm{FeCl}_{3} \cdot 6 \mathrm{H}_{2} \mathrm{O}(0.2 \% \mathrm{w} / \mathrm{v}$ in $95 \%$ aqueous ethanol $)$ were successively added. The solution was made up to $10 \mathrm{ml}$ with $95 \%$ aqueous ethanol. After standing for $1 \mathrm{~min}$, the absorption at $520 \mathrm{~nm}$ was read using a blank solution as a reference, prepared as above but omitting the oil. All the operations during color development were carried out under subdued light. Results were expressed in mg of $\alpha$-tocopherol per $\mathrm{kg}$ of oil (Wong et al., 1988).

\section{Total phenolics (TP) content}

A calibration curve of gallic acid $(0.04-0.40 \mathrm{mg} / \mathrm{ml})$ in methanol was prepared. One $\mathrm{ml}$ of a standard solution of gallic acid, $6 \mathrm{ml}$ of methanol, $2.5 \mathrm{ml}$ of the Folin-Ciocalteau reagent, and $5 \mathrm{ml}$ of $7.5 \% \mathrm{Na}_{2} \mathrm{CO}_{3}$ were added to a $50-\mathrm{ml}$ volumetric flask and reached the final volume with distilled water. The solutions were maintained overnight and the absorbance was read at $765 \mathrm{~nm}$. To measure TP, $2.5 \mathrm{~g}$ of oil was diluted with $2.5 \mathrm{ml}$ of $n$-hexane and extracted three times by 5 -min centrifugations (5000 rpm) with $\mathrm{CH}_{3} \mathrm{OH}: \mathrm{H}_{2} \mathrm{O}(80: 20$ $\mathrm{v} / \mathrm{v}$ ). The extract was added to $2.5 \mathrm{ml}$ of Folin-Ciocalteau reagent and $5 \mathrm{ml}$ of $7.5 \% \mathrm{Na}_{2} \mathrm{CO}_{3}$ in a $50-\mathrm{ml}$ volumetric flask reaching the final volume with distilled water. Results were expressed in mg of gallic acid per kg of oil (Capannesi et al., 2000).

\section{Smoke point}

Smoke point of the oils was measured every 8 hours according to AOCS Official Method Cc 9a-48. About 15 $\mathrm{g}$ of the oils were placed in an aluminum plate and were heated in a constantly increasing rate of temperature. The temperature at which bluish smoke started to appear was measured by a thermometer.

\section{Oxidative stability index (OSI)}

A Metrohm Rancimat model 743 (Herisau, Switzerland) set for 3 -g oil samples at $120{ }^{\circ} \mathrm{C}$ and at an airflow rate of $15 \mathrm{l} \mathrm{h}^{-1}$ was used to measure OSI.

\section{Frying process}

Potato stripes $(7.0 \times 0.5 \times 0.3 \mathrm{~cm})$ were prepared and immersed in water until use. Twenty-gram batches of potato stripes were fried in $2 \mathrm{l}$ of oil. Frying temperature was fixed at $180 \operatorname{deg} \mathrm{C}$ using a bench-top deep-fryer (Tefal model 1250, France) and a digital thermometer. Each batch was fried for 5 min, followed by standing the oil for $15 \mathrm{~min}$. This was repeated for $8 \mathrm{~h}$ per day during four consecutive days. At the end of each $4 \mathrm{~h}$, about $20 \mathrm{~g}$ of the frying oil was filtered into a screw-cap vial and promptly stored in the dark at $-18 \mathrm{degC}$ until use. The oil was not replenished during the frying process. The process were conducted in duplicate (Farhoosh and Moosavi, 2010).

\section{Conjugated diene value (CDV)}

CDV was measured spectrophotometrically at $234 \mathrm{~nm}$ and read against HPLC grade hexane as blank. The oil samples were diluted to 1:600 with hexane. An extinction coefficient of $29000 \mathrm{~mol} \mathrm{l}^{-1}$ was utilized to quantify the concentration of conjugated diene hydrperoxides formed during oxidation (Saguy et al., 1996). 


\section{Carbonyl value (CV)}

The spectrophotometric method developed by Endo et al. (2001) was used to determine the CV of the oils. 2-Propanol and 2,4-decadienal were used as solvent and standard, respectively. The oil samples $(0.04-1.0$ g) were diluted to $10 \mathrm{ml}$ by distilled 2-propanol. One $\mathrm{ml}$ of the solution was introduced into a 15-ml test tube containing $1 \mathrm{ml}$ of 2,4-dinitrophenylhydrazine (DNPH) solution (50 mg of DNPH in $100 \mathrm{ml}$ of 2-propanol containing $3.5 \mathrm{ml}$ of $37 \% \mathrm{HCl}$ ) as an indicator and $8 \mathrm{ml}$ of $\% 2 \mathrm{KOH}$. After centrifugation $(2000 \mathrm{xg}, 5 \mathrm{~min})$, absorbance of the upper layer was read at $420 \mathrm{~nm}$.

\section{Polar compounds analysis}

Total polar compounds (TPC, \%w/w) content of the oils was determined according to the economical micro-method developed by Schulte (2004). Five main alteration components of the polar fractions, including free fatty acids (FFA), diglycerides (DG), oxidized triglyceride monomers (oxTGM), triglyceride dimers (TGD), and triglyceride polymers (TGP), were separated by high-performance size-exclusion chromatography (HPSEC) (Dobarganes et al., 1988). Isolated polar fractions were analyzed in a GPC-SEC chromatograph (Knauer, Berlin, Germany) with a 20- $\mu$ l sample loop. A 2300 refractive index detector and two Nucleogel GPC columns (Macherey-Nagel, Duren, Germany) with 100- and 500- $\AA$ pore size connected in series were operated at $40{ }^{\circ} \mathrm{C}$. The columns were $300 \times 7.7 \mathrm{~mm}$ I.D., packed with a macro-porous, highly cross-linked and spherical polystyrene/divinylbenzene copolymer ( $5 \mu \mathrm{m}$ particle size). HPLC-grade tetrahydrofuran (THF) was used as mobile phase with a flow of $1 \mathrm{ml} \mathrm{min}^{-1}$. Sample concentration was $10 \mathrm{mg} \mathrm{ml}^{-1}$ in THF.

\section{Statistical analysis}

All experiments and measurements were carried out in triplicate, and data were subjected to analysis of variance (ANOVA). ANOVA and regression analysis were performed according to the Minitab and Excel software. Significant differences between means were determined by Duncan's multiple range tests. P values less than 0.05 were considered statistically significant.

\section{Results and discussion}

\section{Characterization of the oils}

Fatty acid composition of VSO, RSO, and ROO was in agreement with those usually reported for sesame and olive oils (Table 1). The oils were of statistically the same amount of SFA (mainly palmitic, C16:0, and stearic, C18:0, acids). ROO was constituted of almost twice amount of MUFA (mainly oleic acid, C18:1) than the sesame oils. Instead, the sesame oils of roughly the same content of PUFA (mainly linoleic acid, C18:2) were considerably more polyunsaturated than ROO. With respect to the relative rate of oxidation reported for linoleic, oleic, and stearic acids as 1200:100:1 (Hsieh and Kinsella, 1989), ROO was definitely to have the most oxidatively stable fatty acid composition.

The sesame oils had acceptable PVs (Table 1) in the range recommended $\left(0.5-1.0\right.$ meq $\left.\mathrm{kg}^{-1}\right)$ for highquality frying oils (Stevenson et al., 1984) but the quite higher value for ROO was in the permitted range ( 10 meq $\mathrm{kg}^{-1}$ for ROOs) promulgated by the International Olive Oil Council (IOOC). Olive oils have been postulated to be comprised of certain components that interfere with the conventional PV measurement, so that even freshly expressed olive oils have PVs of $\sim 10 \mathrm{meq} \mathrm{kg}^{-1}$, or higher values under dry climatic conditions (Firestone, 2005). The AV of VSO was significantly higher than those of RSO and ROO which were statistically the same. The value for high-quality frying oils and refined olive oils should not exceed $\sim 0.2 \mathrm{mg} \mathrm{g}^{-1}$ (Stevenson et al., 1984) and $\sim 0.6 \mathrm{mg} \mathrm{g}^{-1}$ (Firestone, 2005), respectively.

The highest contents of total tocopherols and phenolic compounds were found in VSO, followed by in RSO and ROO (Table 1). Conventional refining processes normally cause significant decreases in the contents of TT (Tasan and Demirci, 2005) and TP (Zacchi and Eggers, 2008). $\alpha$ - and $\gamma$-Tocopherols are recognized as predominant homologues $(\sim 95 \%)$ in olive (Firestone, 2005) and sesame (Hwang, 2005) oils, respectively. The antioxidant activity of tocopherols decreases in the order of $\delta>\gamma>\beta>\alpha$ in fats and oils, while 
in vivo, that is vitamin $\mathrm{E}$ activity, decreases in the order of $\alpha>\beta>\gamma>\delta$ (Wanasundara and Shahidi, 2005). Hydroxycinnamic acids and hydroxytyrosol are known as the main phenolic compounds of the minor fraction of olive oil chemical composition (Boskou, 1999; Pellegrini et al., 2001). Sesamin is the major lignan in sesame oil (Wu et al., 2016), which is in turn transformed into sesamol, episesamin, and sesaminol during refining processes and/or at high temperatures (Wan et al., 2015).

As can be seen in Table 1, ROO exhibited an OSI of about two folds those of the sesame oils. This is likely due to the more contribution of the fatty acid compositions than the anti-oxidative minor components to resist against thermal oxidation under the harsh conditions normally occurring in Rancimat. OSI may essentially not provide a correct estimation of frying stability of an oil, resulting from some inherent differences in the reaction environments established during frying processes and Rancimat test (Habibi-Nodeh et al., 2019).

\section{Frying stability}

\section{Changes in CDV, CV, and TPC}

All the oils studied showed linear trends of change $\left(\mathrm{R}^{2}>0.97\right)$ in $\mathrm{CDV}, \mathrm{CV}$, and TPC with frying time (32 $\mathrm{h}$ at $180{ }^{\circ} \mathrm{C}$ ) (Fig. 1). CDV represents the oxidizability of lipid systems containing methylene-interrupted dienes, which become conjugated during peroxidation (Farmer and Sutton, 1946). Regardless of the slight differences in the initial values, the rate of change in CDV was significantly lower for ROO $(0.72 \mathrm{mmol}$ $\left.\mathrm{l}^{-1} \mathrm{~h}^{-1}\right)$ than for VSO $\left(1.00 \mathrm{mmol} \mathrm{l} \mathrm{l}^{-1} \mathrm{~h}^{-1}\right)$ and RSO $\left(1.84 \mathrm{mmol} \mathrm{l} \mathrm{l}^{-1} \mathrm{~h}^{-1}\right)$ (Fig. 1A). This can be due to the very much lower level of PUFA in ROO than in the sesame oils (Table 1), which makes it less prone to produce conjugated diene hydrperoxides. The better resistance of VSO than RSO to the formation of these oxidation products naturally arises from the greater antioxidant potency of the former (Table 1). Traditional deodorization of sesame oils has been reported to remove sesamol almost completely and more than $85 \%$ of sesamolin and related isomers of sesaminol, leading to markedly reduced oxidative stability of the final product (Kochhar, 2002).

Despite CDV, which stands for conjugated diene hydroperoxides as primary oxidation products, CV represents a wide variety of secondary oxidation products known as aldehydes and ketones. Its level in frying oils is of extreme importance because carbonyls often cause rancidity and off-flavor, and reduce nutritional value of fried foods (Endo et al., 2001). While there was no significant differences among the initial values, ROO revealed the highest susceptibility to secondary oxidation, so that the change in CV for it $(2.31 \mu \mathrm{mol}$ $\left.\mathrm{g}^{-1} \mathrm{~h}^{-1}\right)$ was significantly much faster than those for RSO $\left(1.89 \mu \mathrm{mol} \mathrm{g}-1 \mathrm{~h}^{-1}\right)$ and VSO $\left(1.17 \mu \mathrm{mol} \mathrm{g}^{-1} \mathrm{~h}^{-1}\right)$, respectively (Fig. 1B). This indicates well the greater quantitative and/or qualitative contribution of the predominant antioxidant fractions in the sesame oils ( $\gamma$-tocopherol and lignans) than in ROO ( $\alpha$-tocopherol, hydroxycinnamic acids and hydroxytyrosol) to prevent carbonyls from being formed.

TPC is one of the most well-known and reliable indicators for the extent of chemical deterioration in frying oils. It represents a range of polar components (see below) which are considered to be toxic to human health (Firestone, 1996). With respect to the rates of change in TPC (Fig. 1C), VSO was still of better quality than RSO (0.70 vs. $1.02 \% \mathrm{~h}^{-1}$ ) but there was no much difference between the refined oils in inhibiting the production of polar compounds.

\section{Changes in the polar components}

Figure 2 shows the changes in the contents of thermo-oxidative (oxTGM, TGD, and TGP) and hydrolytic (DG and FFA) polar components during the frying process. This two sets of components differ not only in polarity or molecular weight but also in nutritional impact (Dobarganes et al., 1988), and therefore, it is of crucial importance to specify their distribution for any frying medium over the process.

VSO showed extraordinarily the highest potency in inhibiting the creation of thermo-oxidative polar components during the frying process (Fig. 2A,B,C). Apart from the antioxidant capacity of the tocopherol and phenolic fractions, sesame oils have been shown to include significant amounts of [?] $]^{5}$ - and [?] $]^{7}$-avenasterols capable of an anti-polymerization effect during prolonged heating at high temperatures (Mohamed and Awatif, 1998; Sims et al., 1972). Considering oxTGM as a measure of total oxidation, encompassing both oxygenated 
primary and secondary oxidation products (Ruiz-Mendez et al., 1997), ROO was of slightly weaker strength than RSO to inhibit oxidation in total (Fig. 2A). The refined oils behaved almost similarly with respect to the contents of TGP (Fig. 2C) but ROO was significantly the better frying oil from TGD point of view (Fig. 2B). TGD and TGP, which are oxTGMs linked together preferentially through oxygenated linkages, are very complex and structurally not fully recognized. Nowadays, their summation (TGDP) and a cutoff point of $10 \%$ based on it have absorbed much attention on a health ground (Farhoosh and Tavassoli-Kafrani, 2011). All the oils presented linear trends of change $\left(\mathrm{R}^{2}>0.96\right)$ in TGDP with frying time (Fig. 2D). On the basis of $10 \%$ TGDP, the maximum frying time for VSO was calculated to be $32.1 \mathrm{~h}$, which was considerably higher than the statistically different values for RSO $(13.9 \mathrm{~h})$ and ROO $(15.4 \mathrm{~h})$.

Hydrolytic polar components are also of crucial importance because they are likely to exert pro-oxidant effects and lower increasingly the oxidative stability of frying oils. Monitoring the contents of FFA and DG appeared quite different frying performances for the oils studied (Fig. 2E,F). VSO contained significantly the highest contents of FFA and DG during the frying process and RSO exhibited more resistance than ROO to hydrolytic alterations. As can be seen in Fig. 2E, besides the much smaller quantities compared to DG, FFA showed no given change pattern over time, making it less reliable than DG to determine hydrolysis rate during frying. Higher volatility of FFA than DG causes them to be lost more easily at elevated temperatures (Dobarganes et al., 1988). The more is the content of FFA as well as the tendency to their formation, the lower smoke point for an oil will be. The oils with lower smoke points (especially $<200{ }^{\circ} \mathrm{C}$ ) are less useful for frying operations because they are more prone to the emission of potentially toxic volatile organic compounds (Katragadda et al., 2010). The fresh VSO had a smoke point of $182{ }^{\circ} \mathrm{C}$ which was drastically lower than those of the fresh RSO $\left(231^{\circ} \mathrm{C}\right)$ and ROO $\left(208^{\circ} \mathrm{C}\right)$. As shown in Fig. 3, the smoke points of VSO, RSO, and ROO significantly decreased and reached a plateau $\left(\sim 161^{\circ} \mathrm{C}, \sim 206{ }^{\circ} \mathrm{C}\right.$, and $\sim 190{ }^{\circ} \mathrm{C}$, respectively) after $8 \mathrm{~h}$ of the frying process.

\section{Conclusions}

The present study indicated that relatively less expensive sesame oils with naturally more unsaturated fatty acid compositions could be of equal or even better frying stability relative to olive oils. This demonstrates the remarkable contribution of sesame oils' minor fraction to stabilize the final product. From the thermooxidative alterations standpoint, the virgin sesame oil was shown to be dramatically more stable than the refined olive oil but, hydrolytically, it was not of necessary frying quality due to containing considerable amount of the volatiles decreasing smoke point. Such a deficiency might simply be eliminated by a light deodorization process in a way that the minor anti-oxidative fraction are not be affected significantly. This, of course, will require a separate study to optimize the operational parameters governing the process.

\section{References}

Abou-Gharbia, H.A., Shehata, A.A.Y., \& Shahidi, F. (2000). Effect of processing on oxidative stability and lipid classes of sesame oil. Food Research International , 33 :331-340.

AOCS. (1993). Official methods and recommended practices of the American Oil Chemists' Society. Champaign: AOCS Press.

Bendini, A., Cerretani, L., Carrasco-Pancorbo, A., Gomez-Caravaca, A.M., Segura Carretero, A., \& Fernandez-Gutierrez, A. (2007). Phenolic molecules in virgin olive oils: A survey of their sensory properties, health effects, antioxidant activity and analytical methods. An overview of the last decade. Molecules , $12: 1679-1719$.

Boskou, D. (1999). Non-nutrient antioxidants and stability of frying oils. In: Boskou D and Elmadfa I (eds) Frying of Food . Lancaster: Technomic Publishing, pp.183-204.

Boskou, D. (2003). Frying fats. In: Sikorski ZE and Kolakowska A (eds)Chemical and Functional Properties of Food Lipids. Boca Raton: CRC Press, pp.325-343.

Capannesi, C., Palchetti, I., Mascini, M., \& Parenti, A. (2000). Electrochemical sensor and biosensor for 
polyphenols detection in olive oils. Food Chemistry , 71 :553-562.

Casal, S., Malheiro, R., Sendas, A., Oliveira, B.P.P., \& Pereira, J.A. (2010). Olive oil stability under deepfrying conditions. Food and Chemical Toxicology , $48: 2972-2979$.

Dobarganes, M.C., Perez-Camino, M.C., \& Marquez-Ruiz, G. (1988). High performance size exclusion chromatography of polar compounds in heated and non-heated fats. Fat Science and Technology, 90:308-311.

Endo, Y., Li, C.M., Tagiri-Endo, M., \& Fujimoto, K. (2001). A modified method for the estimation of total carbonyl compounds in heated and frying oils using 2-propanol as a solvent. Journal of the American Oil Chemists' Society, 78 :1021-1024.

Farhoosh, R., \& Moosavi, S.M.R. (2010). Evaluating the performance of peroxide and conjugated diene values in monitoring quality of used frying oils. Journal of Agricultural Science and Technology, 11:173-179.

Farhoosh, R., \& Pazhouhanmehr, S. (2009). Relative contribution of compositional parameters to the primary and secondary oxidation of canola oil. Food Chemistry , 114 :1002-1006.

Farhoosh, R., \& Tavassoli-Kafrani, M.H. (2011). Simultaneous monitoring of the conventional qualitative indicators during frying of sun flower oil. Food Chemistry, 125 :209-213.

Farmer, E.H., \& Sutton, D.A. (1946). Peroxidation in relation to olefinic structure. Transactions of the Faraday Society, $\mathbf{4 2}: 228-232$.

Firestone, D. (1996). Regulation of frying fats and oils. In: Perkins EG and Erickson MD (eds) Deep Frying: Chemistry, Nutrition and Practical Applications . Champaign: American Oil Chemists' Society, pp.323-343.

Firestone, D. (2005). Olive oil. In: Shahidi F (ed) Bailey's Industrial Oil and Fat Products . Hoboken, New Jersey: John Wiley and Sons, Inc., pp.302-333.

Fullana, A., Carbonell-Barrachina, A.A., \& Sidhu, S. (2004). Comparison of volatile aldehydes present in the cooking fumes of extra virgin olive, olive, and canola oils. Journal of Agricultural and Food Chemistry , $52: 5207-5214$.

Habibi-Nodeh, F., Farhoosh, R., \& Sharif, A. (2019). Frying stability time of olive oils estimated from the oxidative stability index. Journal of Food Measurement and Characterization, 13:1831-1838.

Hsieh, R.J., \& Kinsella, J.E. (1989). Oxidation of polyunsaturated fatty acids: Mechanisms, products, and inhibition with emphasis on fish.Advances in Food and Nutrition Research , 33 :233-341.

Hwang, L.S. (2005). Sesame oil. In: Shahidi F (ed) Bailey's Industrial Oil and Fat Products . Hoboken, New Jersey: John Wiley and Sons, Inc., pp.537-576.

Gertz, C., Klostermann, S., \& Kochhar, S.P. (2000). Testing and comparing oxidative stability of vegetable oils and fats at frying temperature. European Journal of Lipid Science and Technology , 102 :543-551.

Katragadda, H.R., Fullana, A., Sidhu, S., \& Carbonell-Barrachina, A.A. (2010). Emissions of volatile aldehydes from heated cooking oils. Food Chemistry , 120 :59-65.

Kochhar, S.P. (2002). Sesame, rice-bran and flaxseed oils. In: Gunstone FD (ed) Vegetable Oils in Food Technology: Composition, Properties, and Uses . Oxford: Blackwell Publishing Ltd., pp.297-326.

Lee, J.Y., Kim, M.J., \& Choe, E.O. (2007). Antioxidant activity of lignan compounds extracted from roasted sesame oil on the oxidation of sunflower oil.Food Science and Biotechnology, 16 :981-987.

Lee, S.W., Jeung, M.K., Park, M.H., Lee, S.Y., \& Lee, J. (2010). Effects of roasting conditions of sesame seeds on the oxidative stability of pressed oil during thermal oxidation. Food Chemistry , 118 :681-685.

Mohamed, H.M.A., \& Awatif, I.I. (1998). The use of sesame oil unsaponifiable matter as a natural antioxidant. Food Chemistry, $62: 269-276$. 
Molina-Garcia, L., Santos, C.S.P., Cunha, S.C., Casal, S., \& Fernandes, J.O. (2017). Comparative fingerprint changes of toxic volatiles in low PUFA vegetable oils under deep-frying. Journal of the American Oil Chemists' Society, $\mathbf{9 4}: 271-284$.

Pellegrini, N., Visioli, F., Buratti, S., \& Brighenti, F. (2001). Direct analysis of total antioxidant activity of olive oil and studies on the influence of heating. Journal of Agricultural and Food Chemistry , 49 :2532-2538.

Ruiz-Mendez, M.V., Marquez-Ruiz, G., \& Dobarganes, M.C. (1997). Relationships between quality of crude and refined edible oils based on quantitation of minor glyceridic compounds. Food Chemistry, 60 :549-554.

Saguy, I.S., Shani, A., Weinberg, P., \& Garti, N. (1996). Utilization of jojoba oil for deep-fat frying of foods.Lebensmittel-Wissenschaft und-Technologie , 29 :573-577.

Schulte, E. (2004). Economical micromethod for determination of polar components in frying fats. European Journal of Lipid Science and Technology , $106: 772-776$.

Shantha, N.C., \& Decker, E.A. (1994). Rapid, sensitive, iron-based spectrophotometric methods for determination of peroxide values of food lipids. Journal of AOAC International , 77 :421-424.

Sims, R.J., Fioriti, J.A., \& Kanuk, M.J. (1972). Sterol additives as polymerization inhibitors for frying oils. Journal of the American Oil Chemists' Society , 49 :298-302.

Stevenson, S.G., Vaisey-Genser, M., \& Eskin, N.A.M. (1984). Quality control in the use of deep frying oils. Journal of the American Oil Chemists' Society ,61:1102-1108.

Tasan, M., \& Demirci, M. (2005). Total and individual tocopherol contents of sunflower oil at different steps of refining. European Food Research and Technology , 220 :251-254.

Wan, Y., Li, H., Fu, G., Chen, X., Chen, F., \& Xie, M. (2015). The relationship of antioxidant components and antioxidant activity of sesame seed oil. Journal of the Science of Food and Agriculture, 95 :2571-2578.

Wanasundara, P.K.J.P.D., \& Shahidi, F. (2005). Antioxidants: science, technology, and applications. In: Shahidi F (ed) Bailey's Industrial Oil and Fat Products . Hoboken, New Jersey: John Wiley and Sons, Inc., pp.430-489.

Wong, M.L., Timms, R.E., \& Goh, E.M. (1988). Colorimetric determination of total tocopherols in palm oil, olein and stearin. Journal of the American Oil Chemists' Society, 65 :258-261.

Wu, R., Ma, F., Zhang, L., Li, P., Li, G., Zhang, Q., \& Wang, X. (2016). Simultaneous determination of phenolic compounds in sesame oil using LC-MS/MS combined with magnetic carboxylated multi-walled carbon nanotubes. Food Chemistry, 204 :334-342.

Zacchi, P., \& Eggers, R. (2008). High-temperature pre-conditioning of rapeseed: A polyphenol-enriched oil and the effect of refining. European Journal of Lipid Science and Technology , 110 :111-119.

Table 1. Fatty acid composition (\%) and initial quality parameters of the virgin sesame (VSO), refined sesame (RSO), and refined olive (ROO) oils. ${ }^{a}$

Parameter

Fatty acids 14:0 16:0 16:1 18:0 18:1 18:2 18:3 20:0 20:1 22:0 SFA ${ }^{\mathrm{b}}$ MUFA ${ }^{\mathrm{c}} \mathrm{PUFA}^{\mathrm{d}} \mathrm{PV}^{\mathrm{e}} \mathrm{AV}^{\mathrm{f}} \mathrm{TT}^{\mathrm{g}}$ content $\mathrm{TP}^{\mathrm{h}}$ content

a Means \pm SD (standard deviation) within a row with the same lowercase letters are not significantly different at $\mathrm{p}<0.05$. ${ }^{\mathrm{b}}$ Saturated fatty acids (\%); ${ }^{\mathrm{c}}$ Monounsaturated fatty acids (\%); ${ }^{\mathrm{d}}$ Polyunsaturated fatty acids (\%); ${ }^{\mathrm{e}}$ Peroxide value (meq $\mathrm{O}_{2}$ per $\mathrm{kg}$ oil); ${ }^{\mathrm{f}}$ Acid value (mg $\mathrm{KOH}$ per g oil); ${ }^{\mathrm{g}}$ Total tocopherols (mg $\alpha$-tocopherol per $\mathrm{kg}$ oil); ${ }^{\mathrm{h}}$ Total phenolic compounds (mg gallic acid per $\mathrm{kg}$ oil); ${ }^{\mathrm{i}}$ Oxidative stability index $(\mathrm{h})$.

\section{Hosted file}


image1.emf available at https://authorea.com/users/401534/articles/513597-frying-stabilityof-virgin-and-refined-sesame-oils-as-compared-to-refined-olive-oil

\section{Hosted file}

image2.emf available at https://authorea.com/users/401534/articles/513597-frying-stabilityof-virgin-and-refined-sesame-oils-as-compared-to-refined-olive-oil

\section{Hosted file}

image3.emf available at https://authorea.com/users/401534/articles/513597-frying-stabilityof-virgin-and-refined-sesame-oils-as-compared-to-refined-olive-oil

Figure 1. Changes in the values of (A) conjugated diene, CDV, (B) carbonyl, CV, and (C) total polar compounds, TPC, of the virgin sesame (VSO), refined sesame (RSO), and refined olive (ROO) oils during the frying process at $180{ }^{\circ} \mathrm{C}$.

\section{Hosted file}

image4.emf available at https://authorea.com/users/401534/articles/513597-frying-stabilityof-virgin-and-refined-sesame-oils-as-compared-to-refined-olive-oil

\section{Hosted file}

image5.emf available at https://authorea.com/users/401534/articles/513597-frying-stabilityof-virgin-and-refined-sesame-oils-as-compared-to-refined-olive-oil

\section{Hosted file}

image6.emf available at https://authorea.com/users/401534/articles/513597-frying-stabilityof-virgin-and-refined-sesame-oils-as-compared-to-refined-olive-oil

\section{Hosted file}

image7.emf available at https://authorea.com/users/401534/articles/513597-frying-stabilityof-virgin-and-refined-sesame-oils-as-compared-to-refined-olive-oil

\section{Hosted file}

image8.emf available at https://authorea.com/users/401534/articles/513597-frying-stabilityof-virgin-and-refined-sesame-oils-as-compared-to-refined-olive-oil

\section{Hosted file}

image9.emf available at https://authorea.com/users/401534/articles/513597-frying-stabilityof-virgin-and-refined-sesame-oils-as-compared-to-refined-olive-oil

Figure 2. Changes in the contents of (A) oxidized triglyceride monomers, oxTGM, (B) triglyceride dimers, TGD, (C) triglyceride polymers, TGP, (D) TGD+TGP, TGDP, (E) free fatty acids, FFA, and (F) diglycerides, DG, of the virgin sesame (VSO), refined sesame (RSO), and refined olive (ROO) oils during the frying process at $180^{\circ} \mathrm{C}$.

\section{Hosted file}

image10.emf available at https://authorea.com/users/401534/articles/513597-frying-stabilityof-virgin-and-refined-sesame-oils-as-compared-to-refined-olive-oil

Figure 3. Changes the smoke points of the virgin sesame (VSO), refined sesame (RSO), and refined olive (ROO) oils during the frying process at $180{ }^{\circ} \mathrm{C}$. Means $\pm \mathrm{SD}$ (standard deviation) for each oil over time with the same lowercase letters are not significantly different at $\mathrm{P}<0.05$. Means $+-\mathrm{SD}$ in each time point with the same uppercase letters are not significantly different at $\mathrm{P}<0.05$. 